\title{
Structural Equation Model into Interaction Mechanism between Forest Industry and Ecology with Environmental Mediator Introduced
}

\author{
Bing Liao, Zhiguang Zhang *, Chunxiang Liu and Yuanzheng Wu \\ College of Economics and Management/System Engineering Institute for Environment and \\ Development, Nanjing Forest University, Nanjing 210037, China; liaobing1002@126.com (B. L.); \\ lyrcherry@163.com (C. L.); njwuyuanzheng@163.com (Y. W.) \\ * Correspondence author: zzg@njfu.com.cn; Tel. /Fax: +86-25-85428389/+86 13951985583
}

\begin{abstract}
By introducing environmental mediator, for avoiding randomness in selecting indicators and subjectivity in deciding interaction path coefficients to reveal interaction mechanism among forest industry, ecology and environmental capacity, structural Pressure-State-Impact-Response (PSIR) and quantitative Structural Equation Modeling (SEM) are utilized with data on thirty-one provinces of China. We can find that: (i) forest industry has a negative influence on ecology, whereas ecology has a positive influence on industry; (ii) the destructive influence that industry has on ecology is much greater than the positive effect ecology has on industry; and (iii) environmental capacity plays a partial mediating role between industry and ecology. According to these results we can conclude that: (i) forest industry and ecology are not in a symbiotic relationship and have not reached a level of ecological security; (ii) the interaction between industry and ecology is in a period of transition from antagonistic to beneficial; and (iii) industry dominates ecology. However, we prospect the following advice: (i) methods of forest industry should be changed; (ii) new modes of industrial integration and circular economy should be developed; and (iii) the ability of the environment to sustain itself should be enhanced. The level of forest ecological security to discuss the symbiotic mechanism of industry and ecology will propose to be measured in future.
\end{abstract}

Keywords: forest industry and ecology; environmental capacity; interaction mechanism; SEM; PSIR

\section{Introduction}

On the occasion of replying to global climate warming and ecological environment crisis, ecological civilization was proposed, poured into five positions in one system, written into the Communist Party Constitution of China, brought into China's Constitution, and rose to a basic national policy. This is not only a great exploration but also a solemn commitment, moreover an important milestone for promoting the procession of human civilization. At the current time ecological civilization construction has been highly valued and widely concerned about at home and abroad. Ecological security is an important symbol of ecological civilization and forest ecological security is an important constituent part of ecological security. The essence of forest ecological security is mutually beneficial symbiosis between forest industry and ecology $[1,2]$ and it contains forest industry security, forest ecological security and symbiotic security of them [3]. From here we can see that forest ecological security has something to do with forest industry and ecology complex systems. Their interaction will come into being non-symbiotic and symbiotic modes. Non-symbiotic modes contain competing against each other, damaging singly, damaging partially modes while symbiotic modes contain partial benefit, mutually benefit symbiotic modes [4]. 
However, their relationship between China's forest industry and ecology is separated and disjointed, which will restrict forest industry development and stumble forest ecology construction. That such as in which pattern is the mutual relationship between forest industry and ecology in China meanwhile what's their interaction mechanism can be further discussed and researched. Thus it's time for us to research into the interaction mechanism between forest industry and ecology in this study meanwhile it has become one of the core strategy problems of forest industry development in China. With these researches into the interaction relationship between forest industry and ecology carried out, we can identify the development modes between forest industry and ecology to reveal their interaction mechanism. At the same time, it plays a guideline role in promoting the procession of forest ecological security and ecological civilization.

The earliest researches on relationship between forest industry and ecology at home and abroad can be tracked to Sustainable Development Concept [5-10] which was put forward at the report Our Common Future by World Environmental Development Commission in 1987. The goal of Sustainable Development Concept is to pursue the mutually benefit symbiosis between forest industry and ecology and it also became a goal of international communities. Hereafter these researches about their relationship are carried out one after another and can be divided into three categories. The first category is about theoretical qualitative researches of their interaction relationship. These researches conclude the conclusion that their interaction contains non-symbiotic and symbiotic relationship and mainly qualitatively discuss the development relationship, importance, reasons, existing problems, their driving paths, etc. The second category is about the quantitative empirical researches of interaction relationship between forest industry and ecology and they mainly contain the measurement of coupling degree by establishing coupling symbiotic models [11-13] which have the following three steps. The first step is to screen the observed and unobserved variables out, including economy, society, environment, resources, ecology, management [14], etc. The second step is to select coupling measurement methods which mainly decide the function path coefficients of indicators. These models include grey relational analysis (GRA) [15], factorial analysis (FA) and principal component analysis (PCA) [16], sequential projection pursuit model [17], Lotka-Volterra symbiotic coordination index model (L-V model) [18], entropy weight method [19], PSIR and SEM [20], multi-index complex evaluation [21], DEA-Tobit method [22], etc. They can be divided into indicators system methods and characteristics index methods. The third step is to measure the coupling degree to judge their development level between forest industry and ecology. The third category is about the practical researches between forest industry and ecology at home and abroad. At abroad some countries (e.g. Finland, Sweden, Germany, Italy, Canada, New Zealand, etc.) take nearly one hundred years to make forest industry and ecology arrive at a complete symbiotic level from non-symbiosis [23], which proves that forest development from non-symbiosis to complete symbiosis can achieve by implementing forest circular economy system, carrying out forest certification system, and putting forward perfect forest policy system, etc. However, China's research on interaction relationship between forest industry and ecology is later than abroad. Although at first relatively perfect system was raised long time ago but failed to achieve the expected efficiency at that time due to low level of economy development, limitation of government financial resources, and society cognition, etc. Thus it is important for us to research into the interaction relationship to reveal the symbiotic mechanism between forest industry and ecology.

In a word, although scholars at home and abroad have studied their interaction between forest industry and ecology in different views, concluded a number of important conclusions, supported a good reference, laid a good foundation and gave an inspiration for this paper, the following fields are expected to be more perfect. (i) Current researches only reveal the interaction mechanism between forest industry and ecology without regard to the impact external environment capacity has on forest industry and ecology, so it is much more convincible for us to study the interaction mechanism through introducing environmental capacity. (ii) The subjectivity in determining function path coefficients with the method of indicator system is large, what's worse, the data needs the standardization procession and the processed data loses the original ecological economy significance so that it is hard to understand. The error from a single index to comprehensive indexes by means of characteristics index methods is also so large that they will lose the original 
ecological economy significance after procession, hard to understand, too. While SEM takes advantage of the two methods and it is widely used in all kinds of fields. (iii) Some selective indicators by means of indicator system methods and characteristics index methods have great randomness and subjectivity, because the two methods have no feedback mechanism of certifying PSIR model and screening indicators out. Therefore structural PSIR and quantitative SEM will be introduced to avoid these. (iv) Some indicators are too detailed to be regarded the auto-correlation while some indicators are too little to completely reflect the characteristics of ecological economy system so that the function path coefficients are so unreasonable. Furthermore the proportion of economic indicators is too much larger than ecological indicators, which is equal to the economic evaluation and lack of research significance.

Therefore with the current existing researches we introduce environment capacity mediator. The objectives of our study are: (i) to utilize PSIR to select the original indicators among forest industry, ecology and environment capacity to get rid of randomness; and (ii) to establish SEM to rectify PSIR, screen and test quantitatively for obtaining the final indicators and function path coefficients for avoiding the subjectivity. The detailed research processions are as follows. Firstly based on qualitative analysis on the structure and operation mechanism between forest industry and ecology complex system, PSIR containing Pressure-State-Impact-Response among forest industry, ecology and environment capacity is constructed to select the original indicators. Secondly structural hypotheses model SMP with environmental partial mediating and structural hypotheses model SMc with environmental complete mediating are respectively built. After these, the empirical model SEMP in partial environmental mediating and SEMc in complete environmental mediating are respectively constructed to test hypotheses models. Finally, the more actually structural model is screened out through comparison of function path coefficients, their interaction mechanism among forest industry, ecology and environment capacity will be revealed in depth, and some conclusions, policies and future prospects are put forward. To be sure, the test results will have four possibilities: (i) when SEMP and SEMc neither passes the tests, feedback mechanism is built to improve qualitative analysis on structure and operation mechanism of forest industry and ecology complex system; (ii) when only SEMP passes the tests and is selective, forest industry and ecology not only have the direct interaction but also the indirect interaction via the environmental capacity; (iii) when only SEMc passes the tests and is selective, forest industry and ecology only have the indirect interaction via the environmental capacity; (iv) when SEMP and SEMc both pass the tests, the higher fitting degree model will be selective. The logical research map of this paper is presented as Figure 1. 


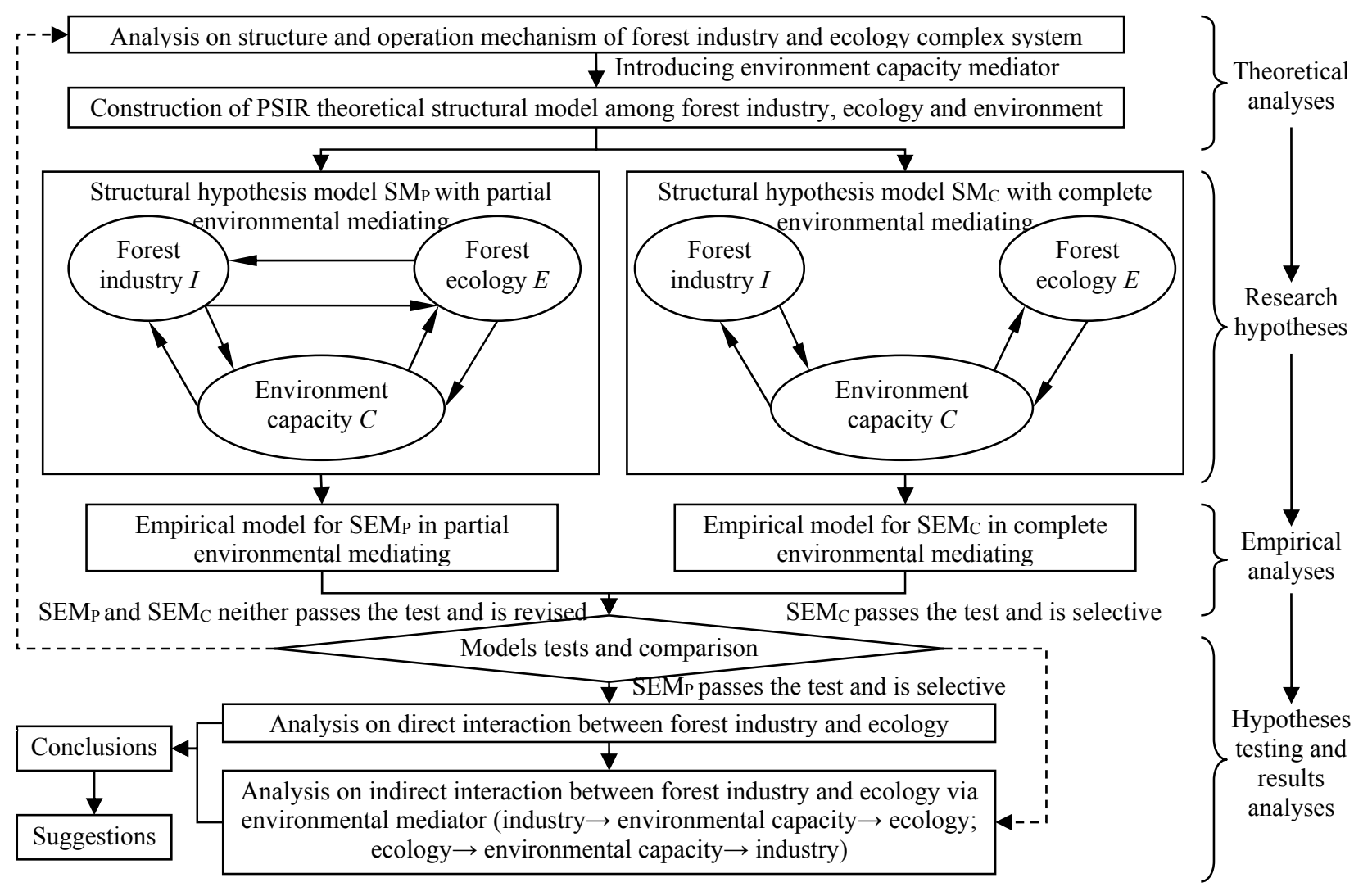

Figure 1. Research map of this paper

\section{Selective original indicators among forest industry, ecology and environmental capacity and theoretic SEM construction}

\subsection{Selection of original indicators among forest industry, ecology and environmental capacity}

After analysis on structure and operation mechanism between forest industry and ecology complex system, we refer to the current existing relational research [20] and comprehensively improve PSR [24], DSR [25], DPSIR [26], DPSEEA [27] models, etc. And then PSIR containing Pressure-State-Impact-Response is built as described in Figure 2. It is made up of four subsystems: (i) P subsystem (Forest industry economy pressure subsystem), involving the pressures from the development of social economy and forest industry that demand forest resources and products; (ii) S subsystem (Resources and environment state subsystem), involving the states such as amount, quality, coverage rate, distribution and type structure of forest resources, as well as the degree of greenhouse gas, etc; (iii) I subsystem (Forest ecology impact subsystem), involving the impacts on health of forest eco-system, forest biodiversity, water and soil loss, air quality, climate warming, etc; (iv) R subsystem (Human beings response subsystem), involving the responses such as human endeavor to improve environment and to plant forests, etc. The unobserved variables forest industry $I$, forest ecology $E$ and environmental capacity $C$ are respectively extracted from $P$ subsystem, I subsystem and S subsystem, R subsystem.

Compared with the existing current researches, some indicators of each subsystem and reverse interaction relationship are added and optimized in Figure 2. In Figure 2, on one hand, the demand pressure of forest industry development for forest production and resources directly has a negative impact on ecology and it can also directly force the pressure into the resources and environment state subsystem to make stock volume of forest, quality of forest resources and forest coverage rate change. At the same time, the changed resources and environment state subsystem has a negative influence on forest ecology impact subsystem so humankind must take measures to protect ecology and improve resources and environment state for reducing the demand pressure of forest industry development. Besides, the demand of forest industry development for forest production and resources can also directly impair the efficiency of measures taken by humankind and destroy the 
forest ecology. On the other hand, forest ecology impact subsystem can directly support forest resources for forest industry development to reduce the pressure. At the same time, forest ecology impact subsystem can also support forests resources for resources and environment state subsystem to reduce the demand pressure of forest industry development. Besides, forest ecology impact subsystem can also directly stimulate the activities taken by humankind to protect environment for reducing the demand pressure of forest industry development.

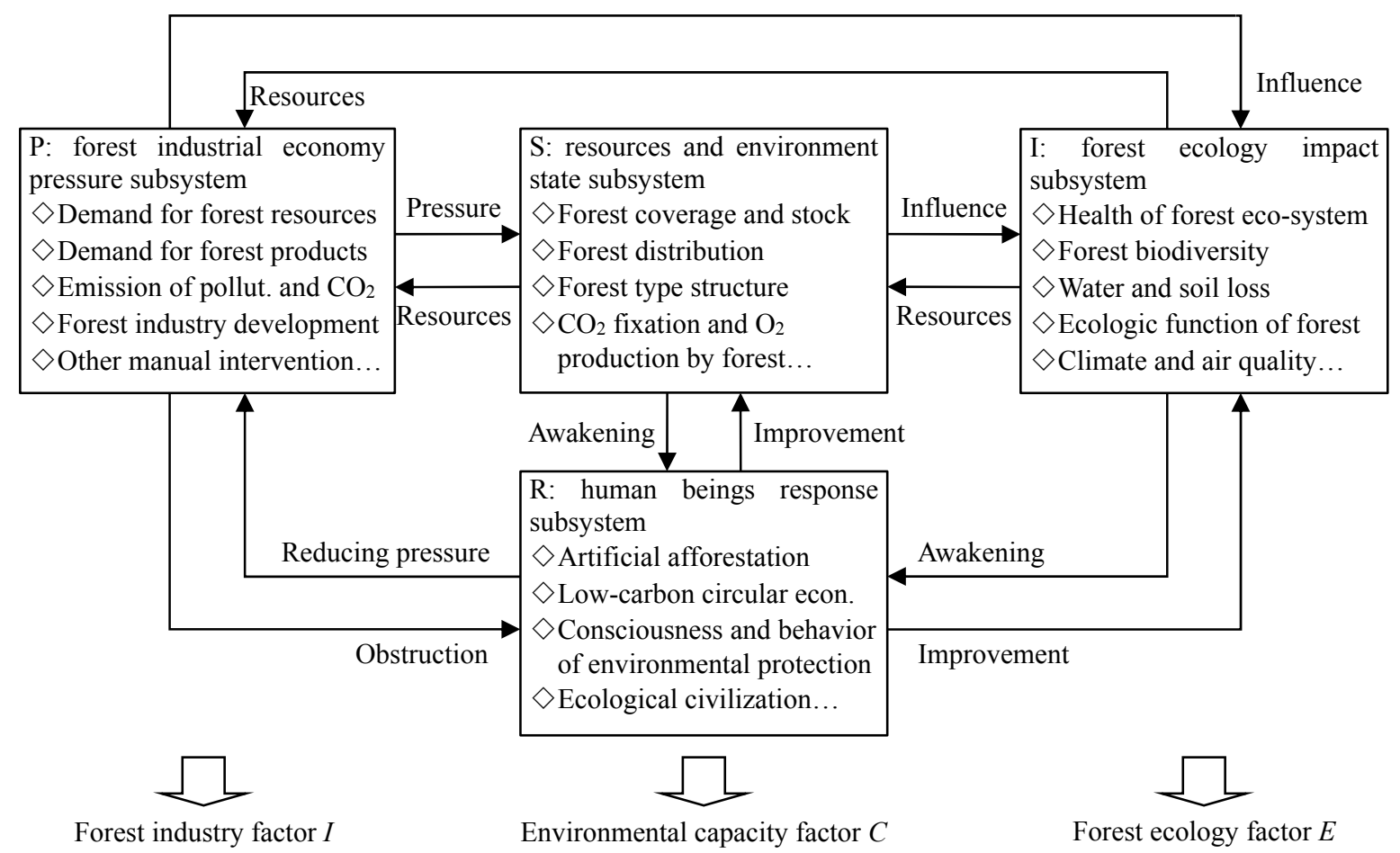

Figure 2. Original indicators among forest industry, ecology and environmental capacity based on PSIR theoretical model

\subsection{Theoretic modeling SEM construction}

Theoretical SEM among forest industry, ecology and environmental capacity is constructed (Figure 3) according to PSIR (Figure 2). Compared with the other traditional econometric models, SEM is able to deal with the unobserved variables and interaction relationship between several reasons and results. By SEM, we can screen out to obtain the final indicators and function path coefficients. SEM contains measurement models and structural models. Measurement models represent the relationship between unobserved variables and observed variables while structural models represent the relationship between unobserved variables and unobserved variables.

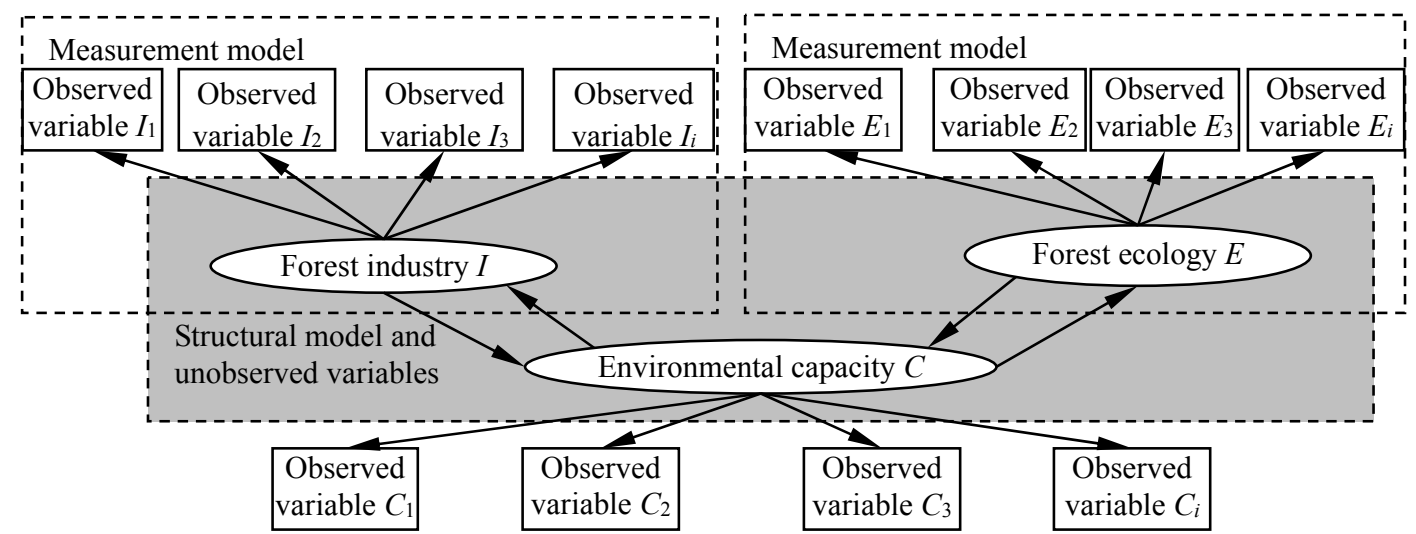

Figure 3. Theoretical SEM among forest industry, ecology and environmental capacity 


\section{Data and procession}

\subsection{Samples and data source}

SEM is so strict about samples that it always needs large samples otherwise it will represent error results. Generally speaking, the quantities of medium samples are more than two hundred. If you want to pursue more suitable model fitting results, the samples whose quantities are less than two hundred will not be encouraged. Therefore, China's thirty-one provinces in 2004 2014 are taken as the research samples, in total three hundred and forty-one samples, suitable to the basic requirement of SEM. Data is from China statistics yearbooks (2005 2015), China forest statistics yearbooks (2004 2014), China environment statistics yearbooks (2004 2014), each province (city, district) national economy and society development statistics bulletins (2004 2014), each province (city, district) statistics yearbooks (2005 2015), in total four thousand seven hundred and seventy-four data.

\subsection{Data procession}

Collected data need procession. The procession of data contains the missing procession and the standardization procession. For the completely missing data which is difficult to observe possible inherent regulations, we directly delete these samples. For the partially probabilistic missing data which is difficult to directly be observed possible inherent regulations but it has some correlation on the other variables, we handle them with the method of mean value or regression analysis. For the non-randomness missing data whose information can be predicted except regulations, we directly remove samples. After missing procession, we carry the standardization procession of positive and negative indicators out. Positive indicators are the larger the better in contrast negative indicators are the larger the worse. In this paper, positive and negative indicators are standardization processed following the method of Zhang [28], respectively (see Equation (1)):

$$
Z_{X_{i}}(t)=\left[X_{i}(t)-X_{i}(t)_{\max }\right] /\left[X_{i}(t)_{\max }-X_{i}(t)_{\min }\right] ; Z_{X_{i}}(t)=\left[X_{i}(t)_{\max }-X_{i}(t)\right] /\left[X_{i}(t)_{\max }-X_{i}(t)_{\min }\right]
$$

where $X_{i}(t)$ represents the index $i$ value of $X$ containing forest industry $I$, forest ecology $E$, environmental capacity $C$ in time $t$. $Z x_{i}(t)$ represents the standardization procession value of $X_{i}$ in time $t\left(0 \leq Z_{X i}(t) \leq 1\right) . X_{i}(t)_{\max }$ and $X_{i}(t)_{\min }$ respectively represent the maximum and minimum values of $X_{i}$ in time $t$.

After data procession, data need to have reliability and validity tested. The PASW software version 18.0 is used to test reliability of data. The Cronbach's $\alpha$ coefficients of forest industry $I$, environmental capacity $C$, forest ecology $E$ are respectively $0.726,0.815,0.849$, above 0.7 and they are significant at a level of 0.01 , representing a good reliability of data (Table 1 ).

Table 1. Results of reliability test

\begin{tabular}{lllllll}
\hline $\begin{array}{l}\text { Unobserved } \\
\text { variables }\end{array}$ & $\begin{array}{l}\text { Cronbach's } \\
\text { coefficients }\end{array}$ & $\begin{array}{l}\text { KMO Standar } \\
\mathbf{d}\end{array}$ & $\begin{array}{l}\text { Estimate } \\
\mathbf{d}\end{array}$ & $\begin{array}{l}\text { Critic } \\
\text { al }\end{array}$ & $\begin{array}{l}\text { Signific } \\
\text { ance } \\
\text { value }\end{array}$ & $\begin{array}{l}\text { rate } \\
\text { tests }\end{array}$ \\
\hline Forest & 0.720 & 0.75 & 0.603 & 1.000 & 14.320 & $* * *$ \\
industry $I$ & & & 0.672 & 1.248 & 14.050 & $* * *$ \\
& & & 0.675 & 1.203 & 13.703 & $* * *$ \\
& & & 0.744 & 1.158 & 12.771 & $* * *$ \\
\hline Environmen & 0.815 & 0.79 & 0.832 & 1.000 & 24.683 & $* * *$ \\
tal & & & 0.752 & 1.070 & 21.263 & $* * *$ \\
capacity C & & & 0.846 & 0.848 & 22.421 & $* * *$ \\
& & & 0.748 & 1.141 & 22.457 & $* * *$ \\
& & & 0.732 & 0.987 & 23.521 & $* * *$ \\
& & & 0.773 & 1.072 & 21.304 & $* * *$ \\
\hline Forest & 0.849 & 0.84 & 0.611 & 0.784 & 13.703 & $* * *$ \\
\hline
\end{tabular}




\begin{tabular}{lllll}
\hline ecology $E$ & 0.554 & 0.836 & 12.102 & $* * *$ \\
& 0.584 & 1.058 & 12.771 & $* * *$ \\
& 0.673 & 1.158 & 19.717 & $* * *$ \\
\hline
\end{tabular}

Notes: The symbol “***” means that correlation is significant at the 0.01 level.

Then AMOS software version 17.0 is utilized to test validity of data. Results show that the estimated standardization value of forest industry $I$, ecology and environmental capacity $C$ are above 0.7 , significant at a level of 0.01 , which shows the clustering validity of unobserved variables are good. The rate of unobserved variables about square root average of variance extraction with correlation coefficients shows they have relatively higher correlation (Table 2).

Table 2. Distinction validity and correlation of unobserved variables

\begin{tabular}{llll}
\hline Unobserved variables Forest & $\begin{array}{l}\text { Environmental } \\
\text { industry } I\end{array}$ & $\begin{array}{l}\text { Forest ecology } \\
\text { capacity } C\end{array}$ \\
\hline Forest industry $I$ & 1 & 0.839 & 0.756 \\
Environmental & 0.839 & 1 & 0.718 \\
$\begin{array}{l}\text { capacity C } \\
\text { Forest ecology } E\end{array}$ & 0.756 & 0.718 & 1 \\
\hline
\end{tabular}

\section{Final indicators among forest industry, ecology and environmental capacity and research hypotheses}

\subsection{Screening results of indicators based on SEM}

The processed and tested data need to be plugged into AMOS software version 17.0 to carry parameters estimation out with the method of Maximum Likelihood Logarithm (MLL) and it will output to obtain the standardized function path coefficients which will also be tested, too. Totally speaking, we tried to screen out and tested indicators above fifty times and selected some significant indicators instead of non significant indicators. At last, forest industry $I$ was represented by forest gross product $I_{1}$, proportion of forest secondary industry $I_{2}$, per capita GDP $I_{3}$, urbanization level $I_{4}$; Environmental capacity $C$ was represented by forest coverage rate $C_{1}$, forest consumption and increase rate $C_{2}$, per capita forest area $C_{3}$, afforestation area rate $C_{4}$, proportion of investment for forest $C_{5}$, treatment rate of industrial pollution $C_{6}$; Forest ecology $E$ was represented by proportion of ecological forest area $E_{1}$, proportion of forest nature reserves area $E_{2}$, water and soil loss area $E_{3}$, air quality index $E_{4}$. We compare the final indicators system with the original indicators (Table 3).

Table 3. Final indicators and function path coefficients among forest industry, ecology and environmental capacity based on SEM

\begin{tabular}{|c|c|c|}
\hline $\begin{array}{c}\text { Unobserved } \\
\text { variables }\end{array}$ & Original indicators system & Final indicators system \\
\hline $\begin{array}{c}\text { Forest } \\
\text { industry } \\
I\end{array}$ & $\begin{array}{l}\text { Forest gross product } X_{1} \text {, Proportion of forest } \\
\text { secondary industry } X_{2} \text {, Proportion of forest gross } \\
\text { product in GDPX } X_{3} \text {, Per capita GDPX } X_{4} \text {, Urbanization } \\
\text { level } X_{5} \text {, Demand for forest product } X_{6} \text {, Forest } \\
\text { pollution emissions } X_{7}\end{array}$ & $\begin{array}{r}\text { Forest gross product } I_{1} \\
\text { Proportion of forest secondary } \\
\text { industry } I_{2} \\
\text { Per capita GDP } I_{3} \\
\text { Urbanization level } I_{4} \\
\text { (Coefficients sum) }\end{array}$ \\
\hline $\begin{array}{c}\text { Environment } \\
\text { capacity } \\
\text { C }\end{array}$ & $\begin{array}{l}\text { Forest coverage rate } X_{8} \text {, forest growing stock } X_{9}, \\
\text { Forest consumption } \& \text { increase rate } X_{10} \text {, Per capita } \\
\text { forest area } X_{11} \text {, Afforestation area rate } X_{12} \text {, } \\
\text { Proportion of investment for forest } X_{13} \text {, Treatment }\end{array}$ & $\begin{array}{r}\text { Forest coverage rate } C_{1} \\
\text { Forest consumption \& increase } \\
{\text { rate }{ }^{1} C_{2}} C_{3}\end{array}$ \\
\hline
\end{tabular}


rate of industrial pollution $X_{14}$, Proportion of forest investment $X_{15}$, Proportion of forest disaster $X_{16}$, Proportion of forest fixed assets investment $X_{17}$
Afforestation area rate $C_{4}$

Proportion of investment for forest $C_{5}$

Treatment rate of industrial pollution ${ }^{2} C_{6}$

(Coefficients sum)

Proportion of ecological forest area $E_{1}$

Proportion of ecological forest area $X_{18}$, Proportion Forest of forest nature reserves area $X_{19}$, Water and soil ecology loss area $X_{20}$, Air quality index $X_{21}$, Per capital public green area $X_{22}$, Proportion of natural reserve zone $X_{23}$
Proportion of forest nature reserves area $E_{2}$

Water and soil loss area $E_{3}$ Air quality index ${ }^{(3} E_{4}$ (Coefficients sum)

Notes: (1) It reflects the dynamic change status of stock volume of forest and it can better reflect the existing situation of forest resources structure and forest supply compared with forest coverage rate. (2) It reflects humankind's consciousness of protecting environment and measurements for environment crisis. (3)It reflects the air ecological situation influenced under the function of forest ecology.

\subsection{Research hypotheses}

The following research hypotheses $\left(\mathrm{H}_{1} \sim \mathrm{H}_{6}\right)$ are raised according to interaction mechanism among forest industry, ecology and environmental capacity.

$\mathrm{H}_{1}$ : The direct influence forest industry has on the ecology represents two possibilities.

(i) H1a: Forest industry has a direct negative influence on the ecology. The demand of forest industry development for forests resources makes humankind's deforestation so as excessively to reduce stock volume of forest and weaken the recovery ability, directly destroying the forest ecology.

(ii) $H_{1 b}$ : Forest industry has a direct positive influence on the ecology. The improvement of the level of forest industry development makes stock volume of forest increase and quality of forest enhance. More forest resources can fix more $\mathrm{CO}_{2}$, let out more $\mathrm{O}_{2}$ and have a better photosynthesis to increase stock volume of forest and restrict the external disturbance, enhancing the level of forest ecology.

$\mathbf{H}_{2}$ : Forest industry has a direct negative influence on the environmental capacity. The demand of forest industry development for forests resources makes humankind's deforestation so as excessively to reduce stock volume of forest and weaken the ability of environmental bearing, making the level of environmental capacity decline.

$\mathbf{H}_{3}$ : Environmental capacity has a direct positive influence on the forest ecology. Environmental capacity could make stock volume of forest increase and forest quality improve, enhancing the ability of environmental bearing and the recovery ability of forest ecosystem to resist interference.

$\mathbf{H}_{4}$ : The direct influence forest ecology has on the industry represents two possibilities.

(i) $\mathbf{H}_{4 a}$ : Forest ecology has a direct positive influence on the industry. Forest ecology could fix more $\mathrm{CO}_{2}$, let out more $\mathrm{O}_{2}$ and have a better photosynthesis to make up more forest organic wood and supply more forest wood for society, promoting the benefit of forest industry economy.

(ii) $\mathbf{H}_{4 b}$ : Forest ecology has a direct negative influence on the industry. Forest ecology could fix more $\mathrm{CO}_{2}$, let out more $\mathrm{O}_{2}$ and have a better photosynthesis to make up more forest organic wood. Due to humankind's so unreasonable activities or measures that forest resources structure will be destroyed, weakening the level of forest industry development.

$\mathbf{H}_{5}$ : Forest ecology has a direct positive influence on the environmental capacity. Forest ecology could fix more $\mathrm{CO}_{2}$, let out more $\mathrm{O}_{2}$ and have a better photosynthesis to make up more forest organic wood, which could increase stock volume of forest to enhance the ability of restricting the external disturbance.

$\mathbf{H}_{6}$ : Environmental capacity has a direct positive influence on the forest industry. Environmental 
capacity could increase stock volume of forest and improve quality of forest to supply more forest production for society to improve the benefit of forest industry economy.

\section{Empirical results, test and analysis}

\subsection{Empirical modeling and identification of model parameters}

The empirical model SEMP in partial environmental mediating and SEMc in complete environmental mediating are respectively established on basis of theoretical research hypotheses. Considering the length of the paper, SEMP, SEMc and theoretical hypotheses $\mathrm{H}_{1} \sim \mathrm{H}_{6}$ are described in Figure 4 together. SEMP and SEMc are distinguished by whether there are two imaginary lines or not. When the two imaginary lines are added, the empirical model SEMP is built to represent that forest industry and ecology not only have the direct interaction, but also the indirect interaction via the environmental capacity. When the two imaginary lines are removed, the empirical model SEMc is constructed to represent that forest industry and ecology only have the indirect influence via the environmental capacity.

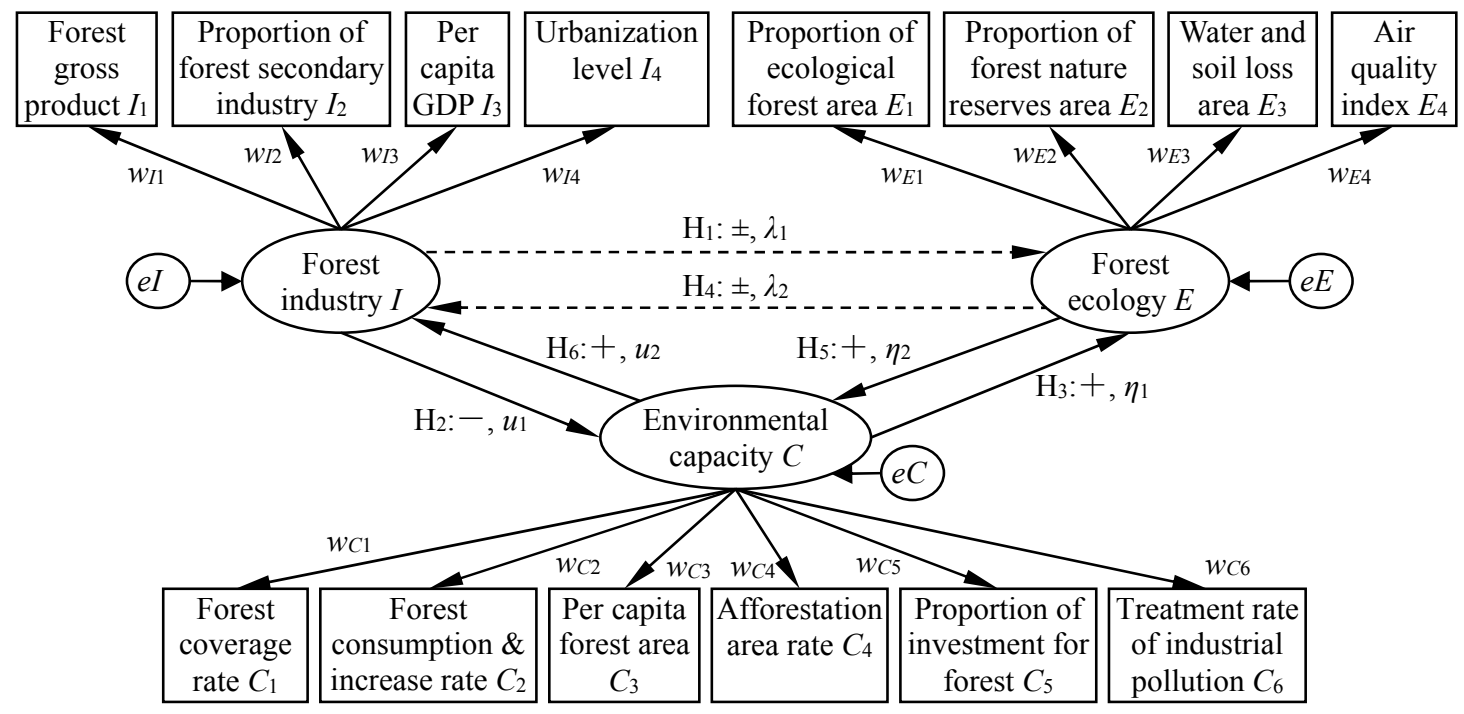

Figure 4. SEM hypotheses model among forest industry, ecology and environmental capacity

SEM structural model equations are estimated as followings:

$$
I_{i}=w_{I_{i}} \times I+e_{I_{i}} ; \quad C_{i}=w_{C_{i}} \times C+e_{C_{i}} ; \quad E_{i}=w_{E_{i}} \times E+e_{E_{i}}
$$

SEM measurement model equations are estimated as followings:

$$
\begin{gathered}
E=\lambda_{1} \times I+e E ; C=u_{1} \times I+e C ; \quad E=\lambda_{1} \times I+\eta_{1} \times C+e E \\
I=\lambda_{2} \times E+e I ; \quad C=\eta_{2} \times E+e C ; \quad I=\lambda_{2} \times E+u_{2} \times C+e I
\end{gathered}
$$

where $I_{i}, C_{i}, E_{i}$ are observed variables and $I, C, E$ are unobserved variables. $w_{l i}, w_{C i}, w_{E i}$ respectively represent the function path coefficients between observed and unobserved variables. $\lambda_{1}, \lambda_{2} ; \mu_{1}, \mu_{2} ; \eta_{1}$, $\eta_{2}$ respectively represent the function path coefficients from $I$ to $E, E$ to $I ; I$ to $C, C$ to $I ; C$ to $E, E$ to $C$. $e_{I I}, e_{C i}, e_{E i}, e_{I}, e_{C}, e_{E}$ respectively represent the residual errors and $i=1,2, \ldots, 6$.

The processed and tested data respectively is plugged into the empirical model SEMP and SEMc to carry parameters estimation out with the method of maximum likelihood logarithmic to outcome the standardization function path coefficients. We test these function path coefficients according to the fitting goodness indexes of SEM. We find although SEMc gets function path coefficients, more than 80 percent of them don't pass the tests of fitting goodness degree, however all the parameters of SEMP pass the tests of fitting goodness degree. Therefore SEMP instead of SEMc is selective, namely the second possibility in "introduction-research map of this paper" above is certified, which shows forest industry and ecology not only have a direct interaction but a indirect interaction via environmental capacity. To be sure in depth, before plugging data into SEMP, we 
rectify the model and screen observed and unobserved variables out. In total, the data is processed above fifty times in order to gain the best indicators and function path coefficients. Regarding the length of the paper, the best fitting indicators results are described in Figure 5 instead of procession results each time. Directed solid lines of forest industry $I$, environmental capacity $C$, forest ecology $E$ represent the influence forest industry has on ecology while directed dot chain lines represent the effect forest ecology has on industry. At the same time, the function path coefficients between unobserved variables and observed variables were also represented in Figure 5.

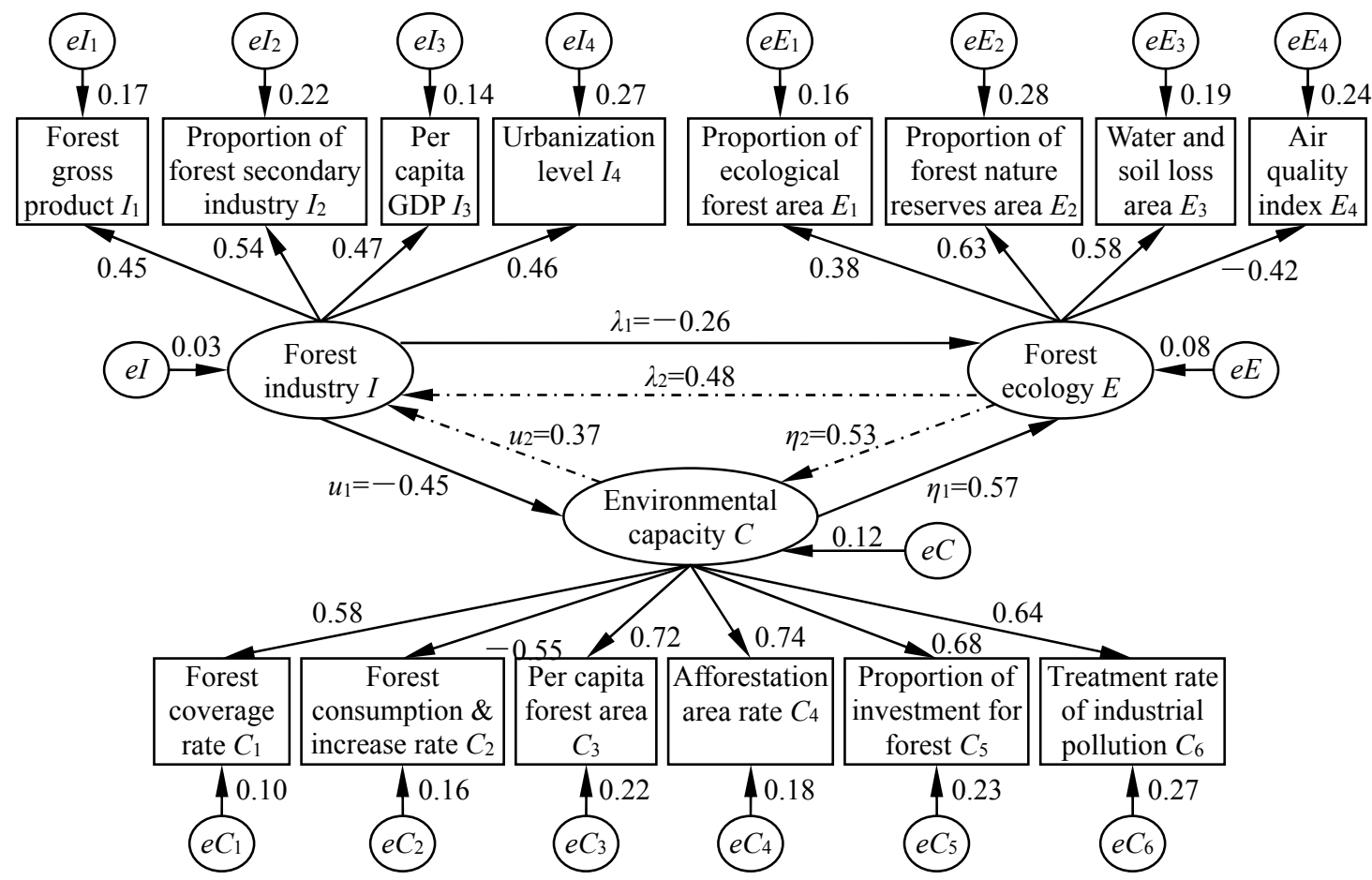

Figure 5. The interaction function path coefficients among forest industry, ecology and environmental capacity

Here equations are utilized to describe the interaction mechanism among forest industry, ecology and environmental capacity. The equations of the impact forest industry has on ecology are as followings:

$$
E=-0.26 \times I+0.08 ; C=-0.45 \times I+0.12 ; E=-0.26 \times I+0.57 \times C+0.08
$$

The equations of the impact forest ecology has on industry are as followings:

$$
I=0.48 \times E+0.03 ; C=0.53 \times E+0.12 ; I=0.48 \times E+0.37 \times C+0.03
$$

\subsection{Test of model parameters}

Table 4 describes the fitting goodness indexes which contain absolute, appreciation and brief fitting indicators in SEMP. The standardization of tests is whether the realistic values are within the judgment standardization or not. Model and data fit well (Table 4): the rate between chi-square value and freedom degree is 1.782 , which is within the scope 1 3; the error mean square root is 0.008 , which is within the scope $0 \sim 0.01$; the other indicators are within reasonable scope.

Table 4. Test results of SEMP about the total fitting goodness indexes

\begin{tabular}{lllll}
\hline $\begin{array}{l}\text { Fitting } \\
\text { indexes }\end{array}$ & Statistics & $\begin{array}{l}\text { Test } \\
\text { value }\end{array}$ & $\begin{array}{l}\text { Judgment } \\
\text { standardization }\end{array}$ & $\begin{array}{l}\text { Test } \\
\text { results }\end{array}$ \\
\hline $\begin{array}{l}\text { Absolute } \\
\text { fitting }\end{array}$ & $\chi^{2}$ (Chi-square value) & 25.330 & $\begin{array}{l}{[0.05,+\infty], \text { The bigger theQualified }} \\
\text { better }\end{array}$ \\
indexes & GFI(Goodness of Fit Index) & 0.857 & $\begin{array}{l}{[0.8,1.0], \text { The bigger theQualified }} \\
\text { better }\end{array}$
\end{tabular}


AGFI(Adjusted Goodness of Fit Index)

RMR(Root Mean Square Residual)

RMSEA(Root Mean Square Error of0.008

Approximation)

NCP(Non-centrality parameter)
$0.873[0.8,1.0]$, The bigger theQualified better

$0.052[0,0.05]$, The smaller theQualified better

$[0,0.01]$, The smaller theQualified better

0.043 [0, 0.05], The smaller theQualified better

AppreciationNFI(Normal Fit Index)

fitting

indexes IFI(Incremental Fit Index)

TLI(Tucker-Lewis Index)

CFI(Comparative Fit Index)

0.998 [0.8, 1.0], The bigger theQualified better

$0.810[0.8,1.0]$, The bigger theQualified better

$0.894[0.8,1.0]$, The bigger theQualified better

$0.867[0.8,1.0]$, The bigger theQualified better

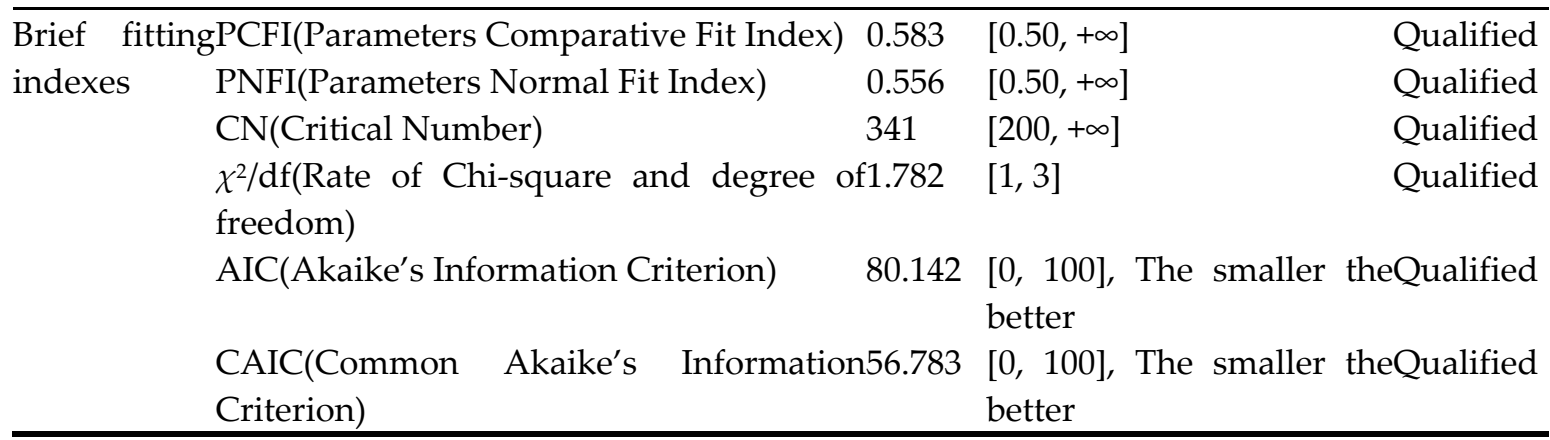

And then whether the model hypotheses and samples data are fitting well or not needs to be tested, too. The test results of the model hypotheses and samples data are presented in Table 5. $\mathrm{H}_{1 \mathrm{~b}}$ and $\mathrm{H}_{4 b}$ neither passes the tests while $\mathrm{H}_{1}, \mathrm{H}_{2}, \mathrm{H}_{3}, \mathrm{H}_{4 a}, \mathrm{H}_{5}$ and $\mathrm{H}_{6}$ are significant at the $1 \%$ level, which proves the model hypotheses are fact.

Table 5. The model fitting results and hypotheses certification

\begin{tabular}{|c|c|c|c|c|c|}
\hline Hypotheses & $\begin{array}{l}\text { Estimated } \\
\text { value }\end{array}$ & $\begin{array}{l}\text { Standard } \\
\text { error }\end{array}$ & $\begin{array}{l}\text { Critical } \\
\text { value }\end{array}$ & Signif & $\begin{array}{l}\text { eHypotheses } \\
\text { certification }\end{array}$ \\
\hline $\mathrm{H}_{1 \mathrm{a}:}$ Forest industry $\rightarrow \operatorname{ecology}(-)$ & $\lambda_{1}=-0.26$ & -0.604 & 11.213 & $* * *$ & Support \\
\hline $\mathrm{H}_{1 b}:$ Forest industry $\rightarrow \operatorname{ecology}(+)$ & $\gamma_{1}=-0.005$ & 0.007 & 0.439 & 0.508 & Not \\
\hline $\begin{array}{l}\mathrm{H}_{2} \text { : Forest industry } \rightarrow \text { environmer } \\
\text { capacity }(-)\end{array}$ & $u_{1}=-0.45$ & -0.736 & 14.187 & $* * *$ & Support \\
\hline $\begin{array}{l}\mathrm{H}_{3}: \text { Environmental capacity } \rightarrow \text { for } \\
\text { ecology }(+)\end{array}$ & $s \mathrm{t} \eta_{1}=0.57$ & 0.559 & 9.831 & $* * *$ & Support \\
\hline $\mathrm{H}_{4 a}:$ Forest ecology $\rightarrow$ industry $(+)$ & $\lambda_{2}=0.48$ & 0.380 & 7.175 & $* * *$ & Support \\
\hline $\mathrm{H}_{4 b}$ : Forest ecology $\rightarrow$ industry $(-)$ & $\gamma_{2}=0.065$ & 0.089 & 0.262 & 0.583 & Not \\
\hline $\begin{array}{l}\mathrm{H}_{5}: \text { Forest ecology } \rightarrow \text { environmer } \\
\text { capacity }(+)\end{array}$ & $\ln \eta_{2}=0.53$ & 0.518 & 6.736 & $* * *$ & Support \\
\hline $\begin{array}{l}\text { H6: Environmental capacity } \rightarrow \text { for } \\
\text { industry }(+)\end{array}$ & $s t u_{2}=0.37$ & 0.326 & 8.105 & $* * *$ & Support \\
\hline
\end{tabular}

Notes: The symbol “***" means that correlations are significant at the 0.01 level.

\subsection{Results and analysis}

Through introducing environmental capacity, SEM was utilized to measure the interaction path coefficients to reveal their interaction mechanism among forest industry, ecology and environmental capacity with data on China's thirty-one provinces 2004 2014 based on PSIR. Here 
we will have the following analysis on results which were as represented in Table 5.

(i) Forest industry has a direct negative influence on ecology (The function path coefficient is 0.26.) and the positive impact coefficient doesn't pass the tests, whereas ecology has a direct positive influence on industry (The function path coefficient is 0.48 .) and the negative influence coefficient doesn't pass the tests. Forest industry supplies economic production for society to get economy benefit while forest ecology supplies ecological services for society to get ecological benefit. As the rational economic persons, forest farmers have deforestation so excessively to get economy benefit for meeting the demand of forest industry development, which makes stock volume of forest reduce rapidly. Because destroying forests is so excessively that forest ecosystem hasn't recovered its function in time, directly damaging ecology environment. On the contrary, forest ecology has the function of retaining water, reserving water and soil, controlling blind and sand, improving climate, absorbing $\mathrm{CO}_{2}$, letting out $\mathrm{O}_{2}$, refreshing air, etc, which can promote forests resources production photosynthesis to speed the formation of forest organic wood for meeting the demand of forest industry development so that it can enhance the level of forest industry.

(ii) Forest industry has a direct negative influence on environmental capacity (The function path coefficient is -0.45 .), whereas environmental capacity has a positive influence on forest industry (The function path coefficient is 0.37.), which are in accordance with the hypotheses. Environmental capacity reflects the max capacity of deforestation in certain research regions. As the rational economic persons, forest farmers have deforestation so excessively to get economy benefit for meeting the demand of forest industry development, which makes stock volume of forest reduce rapidly. Beyond the extent of environmental bearing, the decreasing stock volume of forest weaken the ability of restrict external disturbance and lowers the level of environmental capacity. On the contrary, environmental capacity is on the increase to make stock volume of forest soar, which can supply more forest resources production for society, and to provide more employment opportunities for forest farmers to reduce the pressure of forest economy development, enhancing forest industry development level.

(iii) Environmental capacity has a direct positive influence on ecology (The function path coefficient is 0.57.) in contrast forest ecology has a direct positive influence on environmental capacity (The function path coefficient is 0.53 .), which are in line with the hypotheses. When environmental capacity level increases, stock volume of forest increases to strengthen the bearing ability of resisting the disturbance outside, enhancing the ability of forest ecology self-recovery and forest ecology level. On the contrary, forest ecosystem could supply more forest ecological service and forest resources production for society to increase stock volume of forest, and to enhance the bearing ability of external resources and environment, improving environmental capacity level in the end.

(iv) Forest industry dominates ecology so that the destructive influence forest industry has on ecology is much greater than the positive efficiency forest ecology has on industry. Forest ecology has a direct positive influence on industry, which will make have a symbiotic relationship in the future. But forest industry actually has a direct destructive influence on ecology, which needs several years for forest ecology to get on the normal track.

(v) Forest industry and ecology have the indirect interaction via environmental capacity. Forest industry has a negative influence on the ecology via environmental capacity (The function path coefficient is -0.2565 .), whereas forest ecology has a positive influence on industry via environmental capacity (The function path coefficient is 0.1961.). In detail, forest industry has a negative influence on environmental capacity (The function path coefficient is -0.45.) and environmental capacity has a positive influence on ecology (The function path coefficient is 0.37.), whereas forest ecology has a positive influence on environmental capacity (The function path coefficient is 0.53 .) and environmental capacity has a positive influence on industry (The function path coefficient is 0.57 .), which are in line with the hypotheses. At the same time, these can also illustrate that the interaction between forest industry and ecology is under the restriction of environment capacity. Environmental capacity plays the carrier role between forest industry and ecology. 


\section{Conclusions and policy implications}

Based on PSIR theoretical structure, SEM was conducted to measure interaction function path coefficients to reveal their interaction mechanism among forest industry, ecology and environmental capacity. According to research results above, the following conclusions and policy implications were concluded.

(1) Regarding the current empirical data analysis, China hasn't yet arrived at a level of forest ecological security and forest ecological civilization whose essence is forest industry and ecology symbiosis. In other words, forest industry has a destructive influence on the ecology in contrast forest ecology has a promotion influence on the industry whether forest industry and ecology have a direct or indirect interaction. This represents that the China's forest industry and ecology are not in a symbiotic relationship and haven't yet reached the win-win goal of forest ecological-economy benefit. To coordinate the symbiotic relationship between forest industry and ecology, new modes of industrial integration and circular economy should be developed. (i) The modes of forest-pulp-paper integration should be developed. Forest-pulp-paper integration is the typical case of forest industrial integration. Forest primary industry extends forward and forest secondary extends backward, which can meet the benefit demand and make a contribution to the forest ecology. Forest tertiary industry extends more flexible. In addition, there are mergers, joint management, contracting, leasing, cooperation, joint ventures and other integration modes to be developed, too. (ii) The modes of forest circular economy should be innovated. Forest industry ecology parks putting cities as the center should be established to take most use of advanced technologies to build channels of waste wood recycle, which can develop the mode of pollution-reducing, input-reducing and out-increasing forest circular economy.

(2) The interaction between industry and ecology is in a period of transition from antagonistic to beneficial. Antagonistic is that forest industry and ecology are contradictory whereas beneficial is that forest industry and ecology are complete symbiotic relationship. In terms of the current empirical analyses, relationship between forest industry and ecology is neither contradictory nor symbiosis but in a period of transition, shifting from antagonistic to beneficial. Therefore, methods of forest industry should be changed. (i) Forest industry structure should be adjusted. The advantages of forest industry structure and region competitiveness should be taken to make forest primary industry best, forest secondary industry stronger, forest tertiary industry more flexible, which makes up modern forest industry system. (ii) The forest management departments should pay attention to forest ecology tourism and carry out forest resources certification. At the same time, they should also develop forest ecology.

(3) Environmental capacity plays a partially mediating role between the forest industry and ecology. Forest resources are the precondition and material basis of the interaction between forest industry and ecology. The indirect effect forest industry has on the ecology happens via environmental capacity and forest resources are the restriction condition of interaction between forest industry and ecology. Therefore, the ability of the environment to sustain itself should be enhanced. (i) Forest green technology should be developed. For example, some advanced technology of paper-making dehydration and waste paper fiber procession at abroad should be introduced in order to recycle, reuse, redistribute, replant, cultivate pollution, which can achieve the desired effect of low-input, low-pollution, high-output to construct 5R-3C mode of forest green circular economy. (ii) Forest species should be optimized to increase the degree of plantation establishment to improve stock volume of forest. For example, economy value plants can be planted in the desert governance. Some economic forests and fast-growing forests can be planted to increase stock volume of forest in collective forest zone of south. No floating poplar can be extended to plant to reduce the pollution in the condition area. Quantities of deforestation should be strictly controlled to reasonably utilize forest resources to reduce the consumption of forest resources, and to increase stock volume of forest.

\section{Innovations of research methods of this paper and future research prospects}

Innovations of research methods in this paper show that structural PSIR model and quantitative 
SEM method have an obvious advantage of screening indicators out and determining interaction function path coefficients. On one hand, PSIR provides theoretic basis and logical research framework for selecting the original indicators and constructing SEM. On the other hand, SEM provides objective scientific econometric methods for constructing and correcting PSIR model, selecting indicators out and determining interaction function path coefficients. With regard to future research, the following fields are proposed to research.

(i) The research about the evaluation of forest ecological security with the current calculated interaction function path coefficients expects to be conducted. The essence of forest ecological security is symbiotic relationship security of forest industry and ecology. With the current calculated interaction function path coefficients, forest Lotka-Volterra symbiotic model can be constructed to evaluate forest ecological security level. At the same time, the dynamic change regulations of forest ecological security in views of spatial distribution and time evolution in recent years with thirty-one provinces (cities, districts), China can be analyzed, including the current existing problems, and some detailed observed variables can be traced back to find out the reasons, policies implications, etc, too. The trend of forest ecological security in the future also can be forecasted.

(ii) The evaluation of forest ecological civilization also trends to be researched with some improvement of the current calculated interaction path coefficients. The essence of forest ecological civilization is also the symbiotic relationship security of forest industry and ecology. But forest ecological civilization is different from forest ecological security. With some improvement of indicators, including the current calculated interaction path coefficients, the level of forest ecological civilization by means of forest Lotka-Volterra symbiotic model can be evaluated. At the same time, the dynamic change regulations of forest ecological civilization including the current existing problems can be analyzed in views of spatial distribution and time evolution in recent years with thirty-one provinces (cities, districts), China, and some detailed observed variables can be traced back to find out the reasons, policies implications, etc, too. Besides, the trend of forest ecological civilization in the future can be forecasted.

(iii) The level of forest ecological security and forest ecological civilization propose to be measured in order to discuss the symbiotic mechanism between forest industry and ecology in depth. The essence of forest ecology security and forest ecology civilization is symbiotic mechanism security of forest industry and ecology. The current calculated interaction function coefficients support some reference for future researches about the symbiotic mechanism between forest industry and ecology. In the future, symbiotic relationship model proposes to be constructed to measure symbiotic degree to certify the development level between forest industry and ecology in depth.

Acknowledgements: We are thankful for System Engineering Institute for Environmental and Development of Nanjing Forest University of Nanjing of Jiangsu province, China for constructive revision advice and help with this paper. This work was supported by the Natural Science Foundation, China under Grant number 71673136; the Natural Science Foundation, China under Grant number 71173107; the State Forest Bureau Soft Science Research Program, China under Grant number 2013-R07; the Science \& Technology Department Soft Science Research Program of Jiangsu province, China under Grant number BR2015066; Graduate students innovation engineering projects in 2016 of Jiangsu province under Grant number KYZZ16_0314.

Author Contributions: In this paper, Bing Liao (One author) made the contribution to the conception and design of the study, acquisition of data and analysis, interpretation of data. Zhiguang Zhang (My professor, corresponding author, too) made the contribution to drafting the article and revising it critically for important intellectual content and final approval of the version to be submitted. Chunxiang Liu (Third author) made the contribution to the construction of SEM and the collection of data. Yuanzheng $\mathrm{Wu}$ (Last author) made the contribution to the collection and handling of data 2004 2014. We have participated sufficiently in the work to take public responsibility for the appropriateness of the method, the collection, analysis and interpretation of 
the data.

Conflicts of Interest: The authors declare no conflict of interest. The founding sponsors had no role in the design of the study; in the collection, analyses, or interpretation of data; in the writing of the manuscript, and in the decision to publish the results.

\section{References}

1. Zhang, Z. G. Understanding Mistakes of the Construction for Ecological Civilization. Guangming Daily (Science and Technology Weekly. Ecology Version) the 011th Version, 2015-08-28. (Chinese version)

2. Zhang, Z. G.. Study on ecological civilization from perspective of symbiosis between industry and ecology. J. Central South Univ. For. Tech., 2014, 34(7), 108-114. (Chinese version)

3. Zhang, Z. G.. Methodology for measuring forest ecological security based on ecology-industry symbiosis: a research framework. N. A. Ecol. Sin., 2013, 33(4), 1326-1336. (Chinese version)

4. Xie, Y.; Zhang, Z. G.. Symbiosis Harmonization Mechanism and Patterns between Forest Ecology and Industry System. For. Econ., 2014, 10, 8-11. (Chinese version)

5. Guillermo, M. G.; Ana, M. A.; José Francisco, H. R., et al. Ecological economics, Forest sector, Chiapas, Sustainable development, interdisciplinary knowledge [J]. Nova Scotia, 2010, 2(3), 37-50. [CrossRef]

6. Andy, W. S., Iain, G., Mikael, $\mathrm{H}_{\text {, }}$ et al. Bio-security and sustainability within the growing global bio-economy. Current Opinion in Environ. Sustain., 2011, 3(1-2), 4-10. [CrossRef]

7. Loehmus, A.; Nellis, R.; Pullerits, M.. The Potential for Long-Term Sustainability in Semi-natural Forest: A Broad Perspective Based on Woodpecker Populations. Environ. Manag., 2016, 57(3), 558-571. [CrossRef]

8. Pokharel, R. K., Neupane, P. R., Tiwari, K. R.. Assessing the sustainability in community based forest: A case from Nepal. For. Policy and Econ., 2015, 58(SI), 75-84. [CrossRef]

9. Kindler, E.. Analysis of extended sustainability reporting by state forest services in Germany. Landbauforsch., 2015, 65(2), 131-144. [CrossRef]

10. Moretti, M., De, B. A., Roma, R. Economic and environmental sustainability of forest measures in Apulia Region Rural Development Plan: An application of life cycle approach. Land Use Policy, 2014, 41, 284-289. [CrossRef]

11. Kothonen, J.. Industrial ecosystem the Finnish forest industry: using the material and energy low model of a forest ecosystem in a forest industry system. Ecol. Econ., 2001, 39(1), 145-161. [CrossRef]

12. Van, K. G.. Certification of sustainable forest management practices: a global perspective on why countries certify. For. Policy and Econ., 2005, 7(6), 857-867. [CrossRef]

13. Dong, P. W.; Zhuang, S. Y.; Lin, X. H., et al. Economic evaluation of forest industry based on ecosystem coupling. Mathematical and Computer Model, 2013, 58(5-6), 1010-1017. [CrossRef]

14. Mao, X. P.; Chen, C. H.; Guo, X.; Zhou, D. H., et al. A dynamic assessment of forest ecological security in Changsha-Zhuzhou-Xiangtan area based on PSR model. J. Central South Univ. Forest Tech., 2012, 32(6), 82-86. (Chinese version)

15. Dong, P. W.; Zhang, X. Z. Measurement Study on System Coupling between Forest and Forest Ecosystems. China Soft Sci., 2013, 11, 178-184. (Chinese version)

16. Ning, Z,; Liu, G. C.; Lv, J. H. Research on the Coupling of Forest Ecosystem and Forest Industry of Our Country [D]. Harbin: Northeast For. Univ., 2007. (Chinese version)

17. Song, C. P.; Zhu, C. P.. Study on the Harmonious State of Forest Industry Ecosystem Based on Projection Pursuit Model. For. Econ. Iss., 2015, 25(3), 262-267. (Chinese version)

18. Xie, Y.; Zhang, Z. G.. Harmonious Symbiosis Evaluation Model and its Application for Forest Ecology and Forest Industry System. Nanjing For. Univ., Nanjing, China, 2009. (Chinese version)

19. Chen, Y.; Zhang, Z. G.; XIE, Y., et al. China's Provincial Spatial Distribution for Measuring Forest Ecological Security: Based on Ecology-Industry Symbiosis. J. Agro-For. Econ. Manag., 2015, 14(5), 480-489. (Chinese version)

20. Zhang, Z. G.. Measuring Model and Criterion of Forest Ecological Security by Symbiotic 
Coupling Method. China Population Res. Environ., 2014, 24(8), 90-100. (Chinese version)

21. Shao, X. Q.; Zhang, D. H.; Jin, Y. P.. Study on the forest ecological economic social coupling system and coupling mode in the present age in China. Beijing For. Univ., Beijing, China, 2008. (Chinese version)

22. Liao, B.; Zhang, Z. G.. DEA-Tobit Model of Economics Forests Ecology Economics Efficiency in Ecologically Fragile and Poverty Stricken Regions: A Case Study of Original Central Soviet Areas of Southern Jiangxi. J. Agro-For. Econ. Manag., 2016, 15(2), 179-189. (Chinese version)

23. Mater, J.. The role of the forest industry in the future of the world [J]. For. Products J., 2005, 55(9), 4-11. [CrossRef]

24. Wolfslehner, B.; Vacik, H.. Evaluating sustainable forest management strategies with the analytic network process in a pressure-state-response framework. J. Environ. Manag., 2008, 88(1), 1-10. [CrossRef]

25. United Nation Division of Sustainable Development. Indicators of sustainable development: guideline and methodologies. UNDSD, New York, 2001. (Chinese version)

26. Spangenberg, J. H.; Martinez, A. J.; Omann, I., et al. The DPSIR scheme for analyzing biodiversity loss and developing preservation strategies. Ecol. Econ., 2009, 69(1), 9-11. [CrossRef]

27. Waheed, B.; Khan, F.; Veitch, B.. Linkage-based frameworks for sustainability assessment: making a case for driving force pressure-state-exposure-effect-action (DPSEEA) Frameworks. Sustain. Sci., 2009, 1(3), 441-463. [CrossRef]

28. Zhang, Z. G.. Decision science and art. Sci. Press, Beijing, China, 2006. (Chinese version)

(C) 2016 by the authors; licensee Preprints, Basel, Switzerland. This article is an open access article distributed under the terms and conditions of the Creative Commons by Attribution (CC-BY) license (http://creativecommons.org/licenses/by/4.0/). 